\title{
Au Doping Effect on the Secondary Electron Emission Performance of MgO Films
}

\author{
Jie $\mathrm{Li}^{1}$, Wenbo $\mathrm{Hu}{ }^{1, *}{ }^{\oplus}$, Kang Wang ${ }^{1}$, Buyu Gao ${ }^{1}$, Yongdong $\mathrm{Li}^{1}$, Shengli $\mathrm{Wu}^{1}{ }^{1}$, Jintao Zhang ${ }^{1}$ \\ and Huiqing Fan ${ }^{2}$ \\ 1 Key Laboratory for Physical Electronics and Devices of the Ministry of Education, School of Electronic and \\ Information Engineering, Xi'an Jiaotong University, No. 28, Xianning West Road, Xi'an 710049, China; \\ lijie0814@stu.xjtu.edu.cn (J.L.); wangk5057@stu.xjtu.edu.cn (K.W.); m13689291951@163.com (B.G.); \\ leyond@mail.xjtu.edu.cn (Y.L.); slwu@mail.xjtu.edu.cn (S.W.); zhangjt@mail.xjtu.edu.cn (J.Z.) \\ 2 School of Materials Science and Engineering, Northwestern Polytechnical University, West Youyi Road, \\ Xi'an 710072, China; hqfan@nwpu.edu.cn \\ * Correspondence: huwb@mail.xjtu.edu.cn; Tel.: +86-029-8266-8659
}

Received: 15 September 2018; Accepted: 24 October 2018; Published: 26 October 2018

check for updates

\begin{abstract}
Au-doped $\mathrm{MgO}$ films were prepared by reactive sputtering of individual $\mathrm{Mg}$ and $\mathrm{Au}$ targets, and the Au doping effect on the electron-induced secondary electron emission (SEE) performance was explored by means of surface analysis, first-principle calculation, and electrical characteristic measurement. The results show that the size enlargement of $\mathrm{MgO}$ grains and the reduction of surface work functions induced by Au doping are the main reasons for the increase of the SEE coefficient $(\delta)$. Additionally, the superior SEE degradation property of the Au-doped MgO film under continuous electron bombardment results from the improvement of electrical conductivity. Through the optimization of Au doping concentration (x), Au-doped $\mathrm{MgO}$ film with an $x$ value of $3.0 \%$ was found to have the best SEE performance due to its highest SEE coefficient and longest duration of maintaining a relatively high SEE coefficient; its maximum $\delta$ value reached 11.5-an increase of $32.2 \%$ in comparison with the undoped one.
\end{abstract}

Keywords: Au-doped $\mathrm{MgO}$ films; secondary electron emission; Au doping; first-principle calculation; work function; electrical conductivity

\section{Introduction}

Since its discovery by Campbell, secondary electron emission (SEE) of solid materials has been widely investigated and applied in various electronic information fields such as space navigation, space instruments, night-vision technology, and microanalysis [1-4]. In these fields, solid materials need to have excellent electron-induced SEE performances for achieving the function of electrical signal amplification. Secondary electron emission generally occurs in three steps: (1) production of internal secondary electrons caused by primary electron bombardment; (2) transport of internal secondary electrons towards the material surface; and (3) escape of internal secondary electrons from the material surface. Insulator materials including beryllium oxide, silicon nitride, diamond, and magnesium oxide $(\mathrm{MgO})$ generally exhibit high SEE coefficients $(\delta)$ because of their wide band gaps which can help internal secondary electrons reduce collisions with free electrons and have a greater possibility to be emitted from the material surface [5-8]. Among these materials, $\mathrm{MgO}$ has attracted large amounts of attention due to its favorable antisputtering capability besides its high SEE coefficient [9-11].

Restricted to the insufficient SEE coefficient at various primary electron energies $\left(E_{\mathrm{p}}\right)$ and the surface charging effect under continuous electron bombardment, pure $\mathrm{MgO}$ film is not thought to be one of the best materials to meet the demands of high-gain and long-lifetime vacuum electronic 
devices [12]. As the SEE of a solid material has a close relationship with its surface morphology, electronic structure, and electrical conductivity, many research efforts toward the improvement of the SEE performance, such as substrate temperature rise, Cs termination treatment, and $\mathrm{MgO}$ layer thickness adjustment, have been devoted to $\mathrm{MgO}$ film materials by effecting changes in these physical properties [13-15]. Besides the abovementioned explorations, one of the most promising methods to enhance the SEE performance is the proper doping of other substances in $\mathrm{MgO}$ films. For example, Wang et al. reported that $\mathrm{CoO}$ doping in $\mathrm{MgO}$ films could reduce the surface roughness and thereby result in SEE improvement [16]. Wang et al. prepared $\mathrm{MgO} / \mathrm{Al}_{2} \mathrm{O}_{3}$ composite films on silver substrates and achieved superior SEE properties due to both the presence of $\mathrm{Al}_{2} \mathrm{O}_{3}$ having better resistance to electron bombardment than $\mathrm{MgO}$ and the residual $\mathrm{Al}$ dispersed in the film contributing to good surface charge transfer [17]. Fan et al. proposed $\mathrm{MgO} / \mathrm{Au}, \mathrm{MgO} / \mathrm{Ag}$, and $\mathrm{MgO} / \mathrm{Ni}$ cermet films grown by sputtering of composite targets, and these films were good secondary electron emitters because the presence of metallic particles in the films mitigated the surface charging effect [18]. These research results showed that proper doping in $\mathrm{MgO}$ film could enhance the SEE coefficient. Nevertheless, the SEE performances of these doped $\mathrm{MgO}$ films are not sufficient to meet the demands of high-gain and long-lifetime vacuum electronic devices. Thus, further investigations on the SEE mechanism of doped $\mathrm{MgO}$ films are needed in order to obtain a better secondary electron emitter.

Since $\mathrm{Au}$ has excellent electrical conductivity and chemical stability, the doping of $\mathrm{Au}$ in $\mathrm{MgO}$ films is a possible method to suppress the surface charging effect to improve the SEE performance of MgO films. Early in 1973, Henrich et al. obtained high-efficiency secondary electron emission from a sputtered $\mathrm{MgO} / \mathrm{Au}$ cermet system at substrate temperatures ranging from 50 to $350{ }^{\circ} \mathrm{C}$ [19]. However, its peak SEE coefficient only reached 8. Thus, the SEE performance of the Au-doped MgO films needs to be improved. Unlike previous reports [19,20], in this work, Au-doped MgO films with low doping concentrations $(x)$ were prepared by reactive sputtering of $\mathrm{Mg}$ and Au targets at a relatively higher temperature. Furthermore, the effect of Au doping on the surface morphologies, electronic structures, electrical conductivities, and SEE performances of $\mathrm{MgO}$ films was analyzed in order to elaborate the SEE mechanism of Au-doped MgO films.

\section{Experimental Details}

$\mathrm{Au}$-doped $\mathrm{MgO}$ film samples were prepared by reactive magnetron co-sputtering of high-purity (99.99\%) Mg and Au targets on heavy-doped N-type (100) silicon substrates under the conditions of substrate temperature of $500^{\circ} \mathrm{C}, \mathrm{Ar} / \mathrm{O}_{2}$ gas flow rate of 5:1, and deposition chamber pressure of $0.2 \mathrm{~Pa}$. The $\mathrm{Au}$ doping concentrations in different $\mathrm{MgO}$ film samples were controlled by the sputtering powers of the $\mathrm{Au}$ target. In this work, three $\mathrm{Au}$-doped $\mathrm{MgO}$ film samples with the doping concentrations of $1.5 \%, 3.0 \%$, and $4.5 \%$ and a pure $\mathrm{MgO}$ film sample as a reference were prepared.

For these four samples, their SEE performances were evaluated using a self-designed SEE testing system described in our previous report [13], and their $I-V$ characteristics were measured using a power device analyzer (B1505A, Agilent, CA, USA). Additionally, their surface morphologies and surface roughnesses were characterized using a scanning electron microscope (SEM, JSM-7000F, JEOL, Ltd., Tokyo, Japan) and an atomic force microscope (AFM, Dimension Icon, Bruker, Billerica, MA, USA), respectively.

As first-principle calculations have been widely applied in the analysis of various physical properties [21], the effect of the Au doping concentration on the electronic structure of the $\mathrm{MgO}$ film was analyzed on the basis of first-principle calculations. The band structures and work functions of the undoped and $\mathrm{Au}$-doped $\mathrm{MgO}$ crystals were calculated with the Cambridge Serial Total Energy Package simulation program. $\mathrm{MgO}$ is an ion-type crystal with a face-centered cubic structure and FM-3M space group, and its lattice parameters and bond angles are $\mathrm{a}=\mathrm{b}=\mathrm{c}=0.421 \mathrm{~nm}$ and $\alpha=\beta$ $=\gamma=90^{\circ}$, respectively. A $2 \times 2 \times 2$ supercell containing 32 oxygen atoms and 32 metal atoms was adopted for pure $\mathrm{MgO}$, and $\mathrm{Au}$-doped $\mathrm{MgO}$ supercells were obtained by replacing several $\mathrm{Mg}$ atoms with the same number of $\mathrm{Au}$ atoms. Three Au-doped $\mathrm{MgO}$ supercells with Au atom numbers of 1, 2, and 3 were constructed, and their Au doping concentrations were $1.6 \%, 3.1 \%$, and $4.7 \%$, respectively, 
which were close to the corresponding Au doping concentrations of the abovementioned experimental samples. For the electronic structure calculations, the exchange-correlation potentials among electrons were corrected by local density approximation, and the interaction between ions and electrons was described by ultrasoft pseudopotential. The plane-wave cut-off energy was set at $380 \mathrm{eV}$, and the Brillouin zone sampling mesh parameters for the $k$-point set were $4 \times 4 \times 4$. The total energy and the interaction force between atoms converged to $5 \times 10^{-6} \mathrm{eV} /$ atom and $0.1 \mathrm{eV} / \mathrm{nm}$, respectively, and the internal stress and the displacement were less than $2 \times 10^{4} \mathrm{kPa}$ and $5 \times 10^{-5} \mathrm{~nm}$, respectively.

\section{Results and Discussions}

\subsection{SEE Performances of Au-Doped MgO Films}

Figure 1 showed the dependences of the SEE coefficients of the undoped $\mathrm{MgO}$ film sample and three Au-doped $\mathrm{MgO}$ film samples with $x$ of $1.5 \%, 3.0 \%$, and $4.5 \%$ upon the primary electron energy. It is obviously seen from Figure 1 that for every $\mathrm{MgO}$ film sample, its SEE coefficient has a rapid increase initially and then tends to be saturated as $E_{\mathrm{p}}$ rises, which conforms to the general SEE law of solid materials. It should be noted that the SEE coefficients at various $E_{\mathrm{p}}$ values of every Au-doped $\mathrm{MgO}$ film sample are higher than those of the undoped one, and the SEE coefficient at every fixed $E_{\mathrm{p}}$ value takes on a tendency of increasing firstly and then decreasing with the increase of Au doping concentration. Among these four film samples, the Au-doped $\mathrm{MgO}$ film sample with $x$ of $3.0 \%$ has the highest SEE coefficient and its maximum $\delta$ value reaches 11.5 - an increase of $32.2 \%$ in comparison with the undoped one.

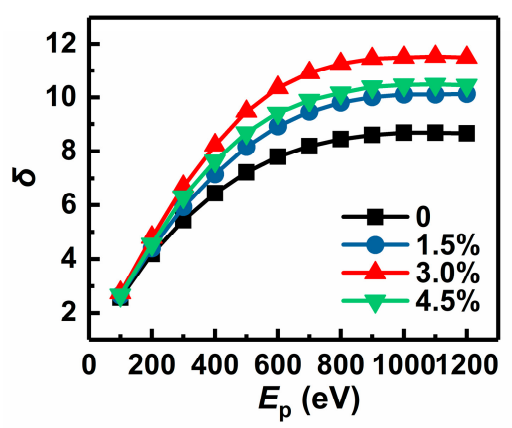

Figure 1. $\delta-E_{\mathrm{p}}$ curves of an undoped $\mathrm{MgO}$ film sample and three Au-doped $\mathrm{MgO}$ film samples with doping concentrations of $1.5 \%, 3.0 \%$, and $4.5 \%$.

In the application of vacuum electronic devices, secondary electron emitters are required to keep a relatively high SEE coefficient for as long as possible under continuous electron bombardment. In order to evaluate the SEE stability of the Au-doped $\mathrm{MgO}$ film samples with different doping concentrations, their SEE coefficient variations with time $(t)$ of electron bombardment at $E_{\mathrm{p}}$ of $200 \mathrm{eV}$ were measured, and their $\delta-t$ curves are shown in Figure 2. During the continuous electron bombardment, every Au-doped MgO film maintains a higher SEE coefficient than the undoped one throughout, and among the three Au-doped MgO film samples, the sample with $x$ of $3.0 \%$ has the highest SEE coefficient. Through calculation, the $2 \mathrm{~h}$ SEE degradation rates of the Au-doped MgO film samples with $x$ of $0,1.5 \%, 3.0 \%$, and $4.5 \%$ are $19.1 \%, 19.0 \%, 19.0 \%$, and $17.7 \%$, respectively, which shows that the SEE degradation is retarded with the increase of the Au doping concentration. It can be concluded that $\mathrm{Au}$ doping in $\mathrm{MgO}$ film can not only improve the SEE coefficients at various $E_{\mathrm{p}}$ values, but also slow down the SEE degradation under continuous electron bombardment. The Au-doped $\mathrm{MgO}$ film sample with $x$ of $3.0 \%$ is considered to have the best SEE performance, because it has the highest SEE coefficient and is speculated to maintain its relatively high SEE coefficient for the longest time under continuous electron bombardment, which better meets the demands of high-gain and long-lifetime vacuum electronic devices. 


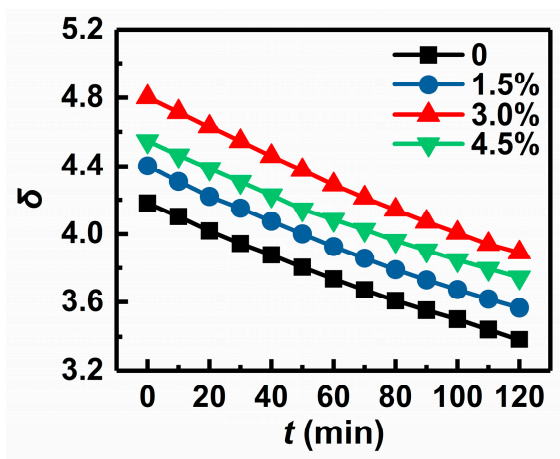

Figure 2. $\delta$ - $t$ curves of an undoped $\mathrm{MgO}$ film sample and three Au-doped $\mathrm{MgO}$ film samples with doping concentrations of $1.5 \%, 3.0 \%$, and $4.5 \%$.

\subsection{Surface Morphologies of Au-Doped $\mathrm{MgO}$ Films}

As surface morphology has a great impact on the SEE of a thin film material [22], SEM micrographs of the abovementioned four $\mathrm{MgO}$ film samples were observed and are shown in Figure 3 for studying the effect of Au doping on the SEE performance of $\mathrm{MgO}$ film. As shown in Figure 3, the mean grain sizes of Au-doped $\mathrm{MgO}$ film samples with $x$ of $0,1.5 \%, 3.0 \%$, and $4.5 \%$ are $27.2 \mathrm{~nm}, 29.7 \mathrm{~nm}, 50.9 \mathrm{~nm}$, and 51.0nm, respectively, which reflects that the $\mathrm{MgO}$ grain size enlarges with the increase of the $\mathrm{Au}$ doping concentration. It is known to us that the $\mathrm{MgO}$ and $\mathrm{Au}$ crystals have the same face-centered cubic structure and similar lattice constants $(0.421 \mathrm{~nm}$ for $\mathrm{MgO}$ and $0.408 \mathrm{~nm}$ for $\mathrm{Au}$ ). Thus, Au doping in $\mathrm{MgO}$ film is conducive to the size enlargement of $\mathrm{MgO}$ grains due to the lattice matching of $\mathrm{MgO}$ and $\mathrm{Au}$ crystals. According to this result, we consider that the increase of SEE coefficient induced by $\mathrm{Au}$ doping described in Figure 1 has a close relationship with the $\mathrm{MgO}$ grain enlargement. The reduction of grain boundary caused by the enlargement of $\mathrm{MgO}$ grains, which decreases the scattering suffered by both the primary electrons injected into the film and the internal secondary electrons moving to the film surface, results in the improvement of the SEE coefficient. However, it should be noted that in comparison with the doped film with $x$ of $3.0 \%$, the Au-doped $\mathrm{MgO}$ film sample with $x$ of $4.5 \%$ has a similar grain size, but its SEE coefficients are greatly lower. In order to find out the reason for this phenomenon, the surface roughnesses of these four $\mathrm{MgO}$ film samples were measured, and the AFM images are shown in Figure 4.

As shown in Figure 4, the root-mean-square roughness $\left(R_{\mathrm{q}}\right)$ of the $\mathrm{MgO}$ film rises with the increase of the Au doping concentration. The increase of surface roughness has a negative effect on the SEE, because the emitted secondary electrons from a rough surface may be recaptured by a locally raised surface [23]. According to the SEM and AFM images of the samples with $x$ of $0,1.5 \%$, and $3.0 \%$, as the Au doping concentration increases, the film surface changes to be rougher, while the SEE coefficient becomes higher. Thus, it can be concluded that in the case of large changes in the surface morphology, the grain size enlargement has a greater effect than does the surface roughness increase on the SEE. In addition, compared with the doped film with $x$ of $3.0 \%$, the sample with $x$ of $4.5 \%$ has a similar grain size but a rougher surface, leading to its lower SEE coefficient. 


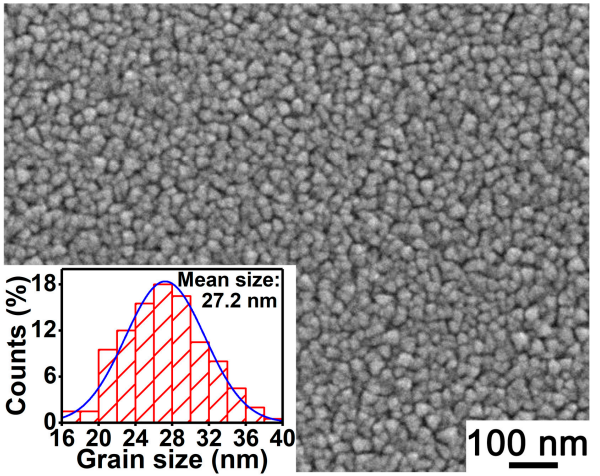

(a)

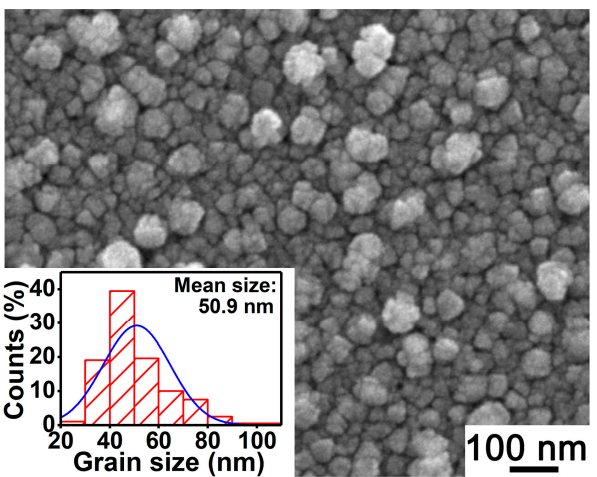

(c)

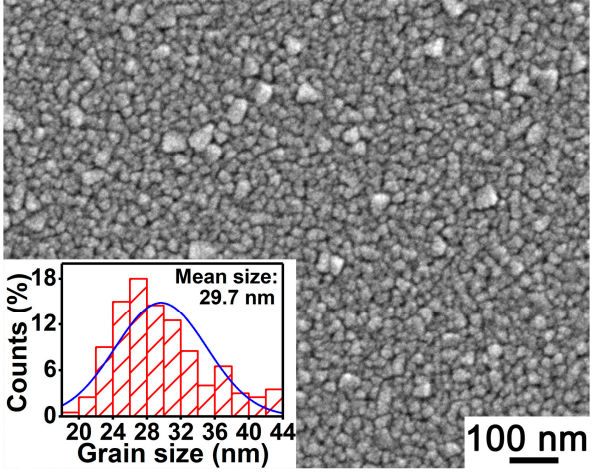

(b)

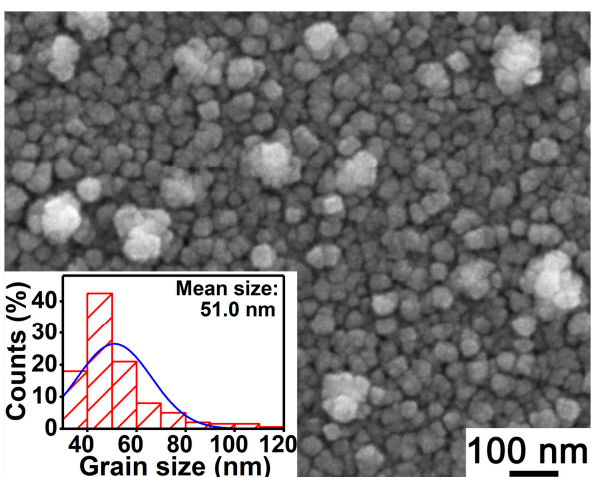

(d)

Figure 3. SEM micrographs and $\mathrm{MgO}$ grain size probability histograms of (a) an undoped $\mathrm{MgO}$ film sample and three Au-doped $\mathrm{MgO}$ film samples with doping concentrations of (b) $1.5 \%$, (c) $3.0 \%$, and (d) $4.5 \%$.

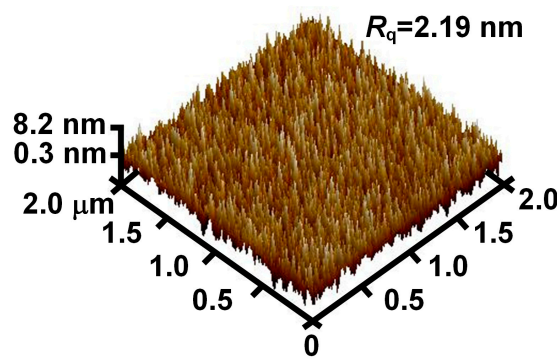

(a)

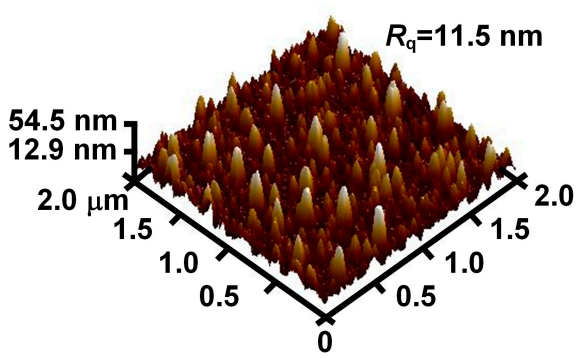

(c)

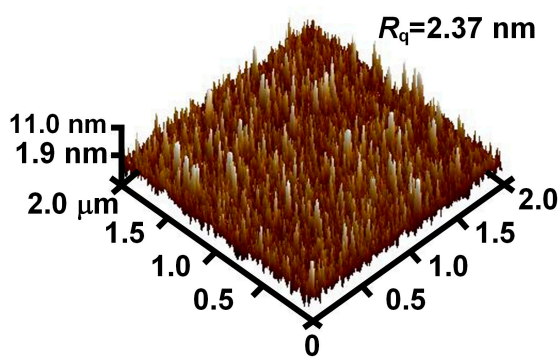

(b)

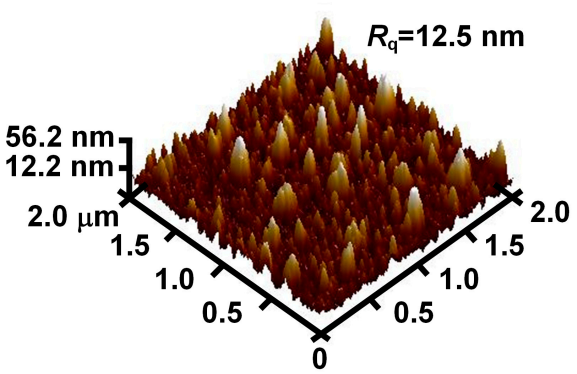

(d)

Figure 4. AFM images of (a) an undoped $\mathrm{MgO}$ film sample and three $\mathrm{Au}$-doped $\mathrm{MgO}$ film samples with doping concentrations of (b) $1.5 \%$, (c) $3.0 \%$, and (d) $4.5 \%$. 


\subsection{Electronic Structures of Au-Doped $\mathrm{MgO}$ Films}

For the purpose of further exploring the Au doping effect on the SEE performance of MgO film, the electronic structures of an undoped $\mathrm{MgO}$ crystal and three $\mathrm{Au}$-doped $\mathrm{MgO}$ crystals with different doping concentrations were obtained by first-principle calculations. Generally, the lower work function of solid materials promotes the generation and escape of internal secondary electrons [24]. As shown in a previous report, $\mathrm{MgO}$ films prepared by reactive sputtering generally exhibited the (200) and (220) crystal planes [25]. Thus, the work functions of the (200) and (220) crystal planes of four Au-doped $\mathrm{MgO}$ crystals with $x$ of $0,1.6 \%, 3.1 \%$, and $4.7 \%$ were obtained by first-principle calculations, as shown in Table 1. Every Au-doped $\mathrm{MgO}$ crystal has obviously reduced work functions of both the (200) and (220) crystal planes in comparison with the undoped one. Additionally, both the work functions of these two crystal planes firstly decrease and then increase as the Au doping concentration rises, and the Au-doped $\mathrm{MgO}$ crystal with $x$ of $1.6 \%$ has the lowest work functions. Thus, the work function reduction induced by Au doping can also lead to the SEE coefficient improvement mentioned in Figure 1.

Table 1. Work functions of the (200) and (220) crystal planes of an undoped MgO crystal and three Au-doped $\mathrm{MgO}$ crystals with doping concentrations of $1.6 \%, 3.1 \%$, and $4.7 \%$.

\begin{tabular}{ccc}
\hline \multirow{2}{*}{ Au Doping Concentration (\%) } & \multicolumn{2}{c}{ Work Function (eV) } \\
\cline { 2 - 3 } & $\mathbf{( 2 0 0 )}$ Crystal Plane & $\mathbf{( 2 2 0 )}$ Crystal Plane \\
\hline 0 & 5.32 & 5.38 \\
1.6 & 1.86 & 2.97 \\
3.1 & 1.92 & 3.25 \\
4.7 & 2.22 & 3.52 \\
\hline
\end{tabular}

On the basis of above investigations, the SEE coefficient variation of the Au-doped $\mathrm{MgO}$ film is closely connected with the changes in $\mathrm{MgO}$ grain size, surface roughness, and work function. Through the comparison between the undoped and $\mathrm{Au}$-doped $\mathrm{MgO}$ film, the SEE coefficient increase of $\mathrm{MgO}$ film induced by $\mathrm{Au}$ doping mainly results from the enlargement of the $\mathrm{MgO}$ grain size and the reduction of the work function. With the Au doping concentration changing from $1.5 \%$ to $3.0 \%$, the grain size enlargement of the Au-doped MgO film is so great that it leads to SEE enhancement, even though the surface roughness and work function increase. As the Au doping concentration increases from $3.0 \%$ to $4.5 \%$, since there is little change in the grain size, so the rougher surface and increased work functions of the $\mathrm{Au}$-doped $\mathrm{MgO}$ film are the two main reasons for the reduction of the SEE coefficient.

Table 2 and Figure 5 show the band gaps and total densities of electronic states (DOS) of the four $\mathrm{MgO}$ crystals with different $\mathrm{Au}$ doping concentrations based on the respective first-principle calculations. It can be seen from Table 2 that the band gaps of Au-doped $\mathrm{MgO}$ crystals with $x$ of 0 , $1.6 \%, 3.1 \%$, and $4.7 \%$ are $4.76 \mathrm{eV}, 2.47 \mathrm{eV}, 2.26 \mathrm{eV}$, and $1.96 \mathrm{eV}$, respectively, which indicates that the band gap of $\mathrm{MgO}$ crystal has an obvious reduction caused by Au doping and it narrows with the increase of the Au doping concentration. It can be seen from Figure 5 that the Au doping leads to the formation of an impurity energy level near the top of the valence band. In addition, both the valence band and the conduction band move to lower-energy positions because of the contribution of Au- $5 \mathrm{~d}$, and the moving distance of the conduction band is further, which leads to the band gap narrowing of Au-doped MgO crystal. 
Table 2. Band gaps of an undoped $\mathrm{MgO}$ crystal and three Au-doped $\mathrm{MgO}$ crystals with doping concentrations of $1.6 \%, 3.1 \%$, and $4.7 \%$.

\begin{tabular}{cc}
\hline Au Doping Concentration (\%) & Band Gap (eV) \\
\hline 0 & 4.76 \\
1.6 & 2.47 \\
3.1 & 2.26 \\
4.7 & 1.96 \\
\hline
\end{tabular}

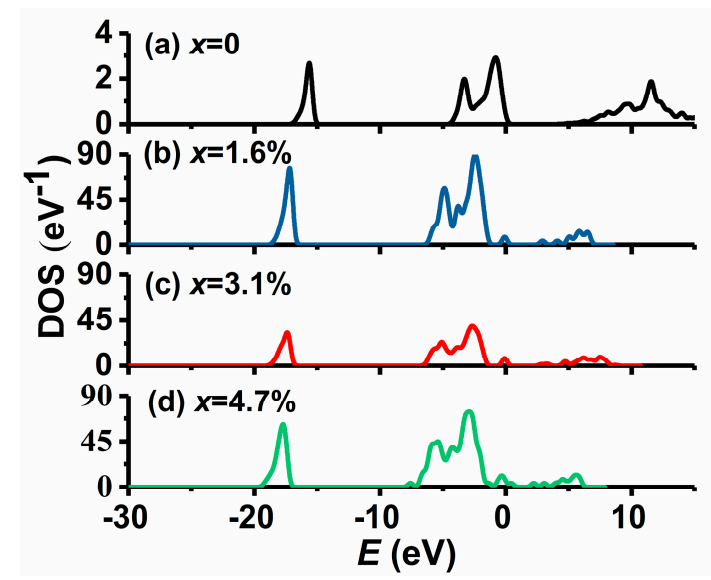

Figure 5. Total densities of electronic states (DOS) of (a) an undoped $\mathrm{MgO}$ film sample and three Au-doped MgO film samples with $x$ of (b) $1.6 \%$, (c) $3.1 \%$, and (d) $4.7 \%$.

\subsection{Electrical Conductivities of Au-Doped MgO Films}

For an SEE film material, electrical conductivity is an important factor in affecting the SEE degradation property. Good electrical conductivity helps the electrons from the substrate easily migrate through the film and reach the surface to neutralize the positive charges, which can reduce the negative effect of surface charging on the SEE under continuous electron bombardment [15]. Thus, the $I-V$ curves of an undoped $\mathrm{MgO}$ film sample and three Au-doped $\mathrm{MgO}$ film samples with different doping concentrations were measured and are shown in Figure 6. It can be evidently seen that the electrical conductivity of Au-doped $\mathrm{MgO}$ film rises with the increase of Au doping concentration due to the high conductivity and good chemical stability of Au. In addition, the band gap narrowing of $\mathrm{MgO}$ film caused by Au doping described in Table 2 is perhaps another important reason for this improvement of electrical conductivity. Since $\mathrm{MgO}$ film is an insulator, surface charging occurs under continuous electron bombardment, which makes the SEE coefficient gradually decrease. The $2 \mathrm{~h}$ SEE degradation rate of $\mathrm{MgO}$ film decreases with the increase of the Au doping concentration described in Figure 2, although a higher SEE coefficient can result in more serious SEE degradation due to a faster charging process. This phenomenon is likely to be connected with the electrical conductivity improvement induced by Au doping. As the electrical conductivity of the $\mathrm{MgO}$ film is improved, the surface charging effect is effectively suppressed; thereby, the SEE coefficient degrades more slowly. 


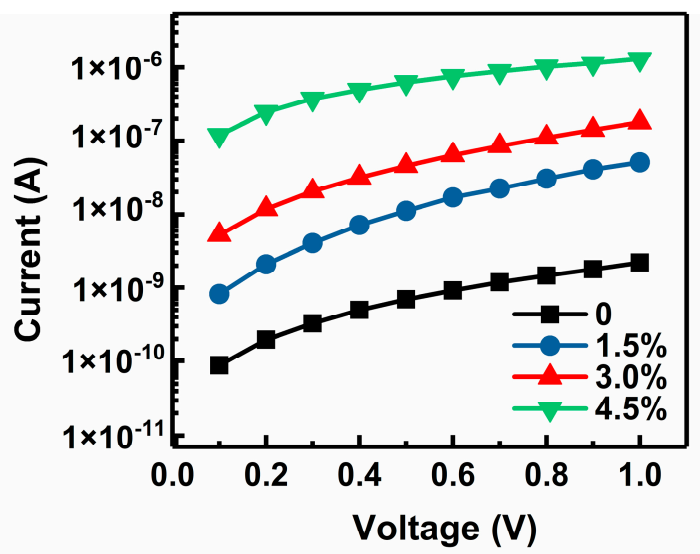

Figure 6. $I-V$ curves of an undoped $\mathrm{MgO}$ film sample and three Au-doped $\mathrm{MgO}$ film samples with doping concentrations of $1.5 \%, 3.0 \%$, and $4.5 \%$.

\section{Conclusions}

In this work, the SEE mechanism of Au-doped $\mathrm{MgO}$ film was investigated through surface analysis, first-principle calculation, and electrical characteristic measurement. According to the experimental results, the enhancement of SEE performance is mainly connected with the enlargement of $\mathrm{MgO}$ grain size, the reduction of surface work function, and the improvement of electrical conductivity of $\mathrm{MgO}$ films caused by Au doping. With the doping concentration of Au-doped $\mathrm{MgO}$ film changing from $1.5 \%$ to $3.0 \%$, the $\mathrm{MgO}$ grain size enlargement has a dominant impact on the increase of SEE coefficient, although the surface roughness and work function rise. However, as the Au doping concentration increases further and reaches $4.5 \%$, the increases of both surface roughness and work function lead to the reduction of the SEE coefficient, since there is little change in the $\mathrm{MgO}$ grain size. As to the SEE degradation property of Au-doped $\mathrm{MgO}$ film, the improvement of electrical conductivity can effectively suppress the surface charging effect and thereby slow down the SEE degradation under continuous electron bombardment.

Author Contributions: Investigation, J.L.; Resources, S.W.; Methodology, J.L. and J.Z.; Data Curation, K.W. and B.G.; Writing-Original Draft Preparation, J.L.; Writing-Review and Editing, J.L. and W.H.; Visualization, K.W. and H.F.; Supervision, W.H. and Y.L.; Project Administration, W.H., S.W. and Y.L.; Funding Acquisition, W.H., S.W. and Y.L.

Funding: This research was funded by National Natural Science Foundation of China, grant numbers U1537210, 61275023, and 61771383.

Acknowledgments: The authors are grateful to Northwest Institute for Non-ferrous Metal Research for providing the experimental support.

Conflicts of Interest: The authors declare no conflict of interest.

\section{References}

1. Wang, Y.; Zhu, X.; Gao, L.; Chen, H. High gain, low noise, and long lifetime MCP electron multiplier for cesium clock. In China Satellite Navigation Conference (CSNC) 2017 Proceedings: Volume III, Proceedings of the China Satellite Navigation Conference, Shanghai, China, 23-25 May 2017; Springer: Singapore, 2017; pp. 575-581.

2. Funsten, H.; Harper, R.; Dors, E.; Janzen, P.; Larsen, B.; Macdonald, E.; Poston, D.; Ritzau, S.; Skoug, R.; Zurbuchen, T. Comparative response of microchannel plate and channel electron multiplier detectors to penetrating radiation in space. IEEE Nucl. Sci. 2015, 62, 2283-2293. [CrossRef]

3. Tao, S.; Chan, H.; Graaf, H. Secondary electron emission materials for transmission dynodes in novel photomultipliers: A review. Materials 2016, 9, 1017. [CrossRef] [PubMed]

4. Kirk, T.; Scholder, O.; Pietro, L.; Ramsperger, U.; Pescia, D. Evidence of nonplanar field emission via secondary electron detection in near field emission scanning electron microscopy. Appl. Phys. Lett. 2009, 94, 153502. [CrossRef] 
5. Wang, B.; Wu, E.; Wang, Y.; Xiong, L.; Liu, S. Activation treatment effects on characteristics of BeO layer and secondary electron emission properties of an activated Cu-Be alloy. Appl. Surf. Sci. 2015, 355, 19-25. [CrossRef]

6. Stacey, A.; Prawer, S.; Rubanov, S.; Akhvlediani, R.; Michaelson, S.; Hoffman, A. Temperature enhancement of secondary electron emission from hydrogenated diamond films. J. Appl. Phys. 2009, 106, 063715. [CrossRef]

7. Zhang, Q.; Wang, J.; Zhou, F.; Liu, W.; Wang, F.; Lai, C. Influence of activation parameters on the thickness of $\mathrm{MgO}$ thin film on Ag-3Mg alloy and its secondary electron emission property. Mater. Res. Bull. 2017, 96, 35-39. [CrossRef]

8. Tao, S.; Theulings, A.; Smedley, J.; Graff, H. DFT study of electron affinity of alkali metal termination on clean and oxygenated $\beta-\mathrm{Si}_{3} \mathrm{~N}_{4}$. Diam. Relat. Mater. 2015, 58, 214-220. [CrossRef]

9. Hine, K.; Yoshimura, S.; Ikuse, K.; Kiuchi, M.; Hashimoto, J.; Terauchi, M.; Nishitani, M.; Hamaguchi, S. Measurement of magnesium oxide sputtering yields by He and Ar ions with a low-energy mass-selected ion beam system. Jpn. J. Appl. Phys. 2007, 46, L1132-L1134. [CrossRef]

10. Ritz, V.; Shih, A.; Sobbcinski, B. Performance of $\mathrm{MgO} / \mathrm{Au}$ cermet films as secondary electron emission cold cathodes. Surf. Interface Anal. 1992, 18, 514-524. [CrossRef]

11. Yi, W.; Yu, S.; Lee, W.; Han, I.; Jeong, T.; Woo, Y.; Lee, J.; Jin, S.; Choi, W.; Heo, J.; et al. Secondary electron emission yields from $\mathrm{MgO}$ deposited on carbon nanotubes. J. Appl. Phys. 2001, 89, 4091-4095. [CrossRef]

12. Caron, M.; Geittner, P.; Much, G. Electron induced degradation of e-beam evaporated MgO layers. Surf. Sci. 2003, 528, 97-102. [CrossRef]

13. Li, J.; Hu, W.; Hao, L.; Wu, S.; Zhang, J. Influence of the substrate temperature on the microstructure and electron-induced secondary electron emission properties of $\mathrm{MgO} / \mathrm{Au}$ composite film. Mater. Res. Bull. 2018, 100, 308-312. [CrossRef]

14. Henrich, V.; Fan, J. Effect of cesiation on secondary-electron emission from MgO/Au cermets. J. Appl. Phys. 1974, 45, 5484-5486. [CrossRef]

15. Lee, J.; Jeong, T.; Yu, S.; Jin, S.; Heo, J.; Yi, W.; Jeon, D.; Kim, J. Thickness effect on secondary electron emission of $\mathrm{MgO}$ layers. Appl. Surf. Sci. 2001, 174, 62-69. [CrossRef]

16. Wang, B.; Xiong, L.; Liu, S. MgO secondary electron emission film prepared by radio-frequency reactive sputtering. Acta Metall. Sin. 2016, 52, 10-16. [CrossRef]

17. Wang, F.; Zhou, F.; Wang, J.; Liu, W.; Zhang, Q.; Yin, Q. Characterization of $\mathrm{MgO} / \mathrm{Al}_{2} \mathrm{O}_{3}$ composite film prepared by DC magnetron sputtering and its secondary electron emission properties. J. Electron. Mater. 2018, 47, 4116-4123. [CrossRef]

18. Fan, J.; Henrich, V. Preparation and properties of sputtered $\mathrm{MgO} / \mathrm{Au}, \mathrm{MgO} / \mathrm{Ag}$, and $\mathrm{MgO} / \mathrm{Ni}$ cermet films. J. Appl. Phys. 1974, 45, 3742-3748. [CrossRef]

19. Henrich, V.; Fan, J. High-efficiency secondary-electron emission from sputtered $\mathrm{MgO}-\mathrm{Au}$ cermets. Appl. Phys. Lett. 1973, 23, 7-8. [CrossRef]

20. Ritz, V. Deposition of $\mathrm{MgO} / \mathrm{Au}$ cermet films by triode sputtering and their characterization. Surf. Interface Anal. 1990, 15, 173-179. [CrossRef]

21. Tao, S.; Theulings, A.; Prodanovic, V.; Smedley, J.; Graaf, H. Optical properties of silicon-rich silicon nitride $\left(\mathrm{Si}_{\mathrm{x}} \mathrm{N}_{\mathrm{y}} \mathrm{H}_{\mathrm{z}}\right)$ from first principles. Computation 2015, 3, 657-669. [CrossRef]

22. Cheng, Y.; Kupfer, H.; Paraian, A. Deposition of $\mathrm{MgO}$ films by pulsed mid-frequency magnetron sputtering. Appl. Surf. Sci. 2002, 200, 117-124. [CrossRef]

23. Suharyanto; Yamano, Y.; Kobayashi, S.; Michizono, S.; Saito, Y.; Tumiran. Effect of mechanical finishes on secondary electron emission of alumina ceramics. IEEE Trans. Dielectr. Electr. Insul. 2007, 14, 620-626. [CrossRef]

24. Vida, G.; Beck, I.; Josepovits, V.; Gyor, M.; Deak, P. Electron beam induced secondary emission changes investigated by work function spectroscopy. Appl. Surf. Sci. 2004, 227, 87-93. [CrossRef]

25. Li, H.; Hu, W.; Wu, S.; Wei, Q. Synthesis and characterization of Microstructures of MgO/Au composite films grown by reactive RF magnetron sputtering. Chin. J. Vac. Sci. Technol. 2014, 34, 842-846. [CrossRef]

(C) 2018 by the authors. Licensee MDPI, Basel, Switzerland. This article is an open access article distributed under the terms and conditions of the Creative Commons Attribution (CC BY) license (http:/ / creativecommons.org/licenses/by/4.0/). 